\title{
AFRIKAANSCHE RESTEN IN DE CREOLENTAAL VAN SURINAME
}

DOOR

LOU LICHTVELD

II

II. DE WEST-SOEDANEESCHE GRONDSLAGEN

$\S 1$. De Soedaneesche taalfamilies. De weinige geleerden die zich met de neger-mengtalen van Nederl. Guyana hebben bezig gehouden, zijn allen eensgezind geweest in de bewering dat het Afrik. element in die talen in hoofdzaak afkomstig is uit het Tsji en het Ewe, twee talen die aan de Goudkust, aan de rechter- en linkeroever van de Voltamonding worden gesproken.

Men heeft dit nagenoeg eenstemmig beweerd ${ }^{\mathbf{1}}$ ), en vond daarvoor twee onaantastbare bewijzen: het feit dat deze kustdialecten thuis behoorden bij de hoofdpunten van de slavenexport, en het feit dat in het N.E. zeer veel woorden en een aantal verschijnselen uit het Tsji en het Ewe werden gevonden. Alleen Schuchardt, gewend aan de voetangels en klemmen die in alle creool-talen den onderzoeker bedreigen, heeft zich over dit punt slechts zeer vaag uitgelaten, en eerst een ervaren Africanist als Maurice Delafosse heeft zich over de stam-talen der Americaansche negerdialecten vager, en daarbij toch juister uitgesproken toen hij zeide ${ }^{2}$ ): ,Il semble que le groupe éburneo-dahoméen soit celui qui a fourni l'appoint le plus considérable et le plus persistant." En deze uitspraak is des te leerzamer, wanneer wij weten, dat Delafosse tot genoem-

1) O.a. v. Ginneken, Handb. I, p. 268, Encycl. v. W. I. p. 504 1. v. Ginneken en Endepols, De regenboogkleuren p. $238 \mathrm{vlg}$.

$\left.{ }^{2}\right)$ Les langues du m. pag. 560. 
de groep niet minder dan 48 talen en dialecten rekent. Terwijl wij nu aanstonds zullen bemerken dat er geen redenen zijn om in het N.E. speciale Tsji- en Ewe-invloeden te zien, laat zich de vroegere onjuiste bewering toch uit verschillende feiten verklaren. Eerstens is het N.E. in zijn geheel nooit fundamenteel behandeld, en zeker niet door iemand die daarbij voldoende africanist was. Daarenboven is eenige nadere kennis van die Afr. talen vrij recent, en een ietwat breedere en samenvattende kijk op de verschillende taalgroepen van Afrika is ons zelfs pas sedert kort vergund.

Van de talen die als stamouders voor hetN.E. in aanmerking komen, waren toevallig het Tsji en het Ewe reeds tamelijk vroeg, en vollediger dan andere dialecten bekend. Daardoor heeft men dan ook het eerst parallellen met deze talen getrokken. De conclusies bij een onvoldoende kennis konden echter slechts een voorloopig karakter dragen, want de jongste vorderingen der Africanisten stellen ons eerst thans in staat, de filiatie van het N.E. met een ietwat ruimere blik te overschouwen.

Intusschen had het niet geringe aantal woorden en verschijnselen uit bijv. het Kongo, die reeds tamelijk vroeg werden gesignaleerd ${ }^{\mathbf{1}}$ ), de onderzoekers kunnen leeren, dat de scheppers van het N.E. niet alleen Asjantijnen waren, en dat de Bantoe-talen daarbij ook hun aandeel gehad hebben.

Wat echter het Tsji en Ewe betreft, deze twee talen worden slechts in een zeer klein gedeelte gesproken van de landstreek ingesloten tusschen Sénégal en Niger, de landstreek die het achterland vormde van de belangrijkste factorijen welke de slaven voor het toenmalig Nederl. Guyana leverden. Volgens Delafosse zijn tusschen Senegal en Niger nog te vinden:

de „Groupe sénégalo-guinéen” (24 talen);

de "Groupe éburneo-dahoméen" (48 talen);

de "Groupe éburneo-libérien" (24 talen);

de Volta-groep (53 talen)

en nog belangrijke gedeelten uit de „Groupes nigéro-sénégalais, nigéro-camerounien en basnigérien", welke 1) Bijv. door Focke, 1855. 
beide laatste de overgang naar de bantoe-groep vormen.

Dezelfde talengroepen verdeelt Westermann in:

Benue-Crossflusz-Sprachen

Mossi-Grussi

Westatlantische

Togo-Restsprachen

Kwa-Sprachen (w. o. Lagunenspr.)

Mandingo-Sprachen.

Aan deze verdeeling zullen wij ons in dit hoofdstuk houden, daar deze groepeering van zuiver Soedaneesch taalstandpunt geschiedt ${ }^{\mathbf{1}}$ ).

Het blijkt momenteel nog van weinig nut om de betrekkingen van al deze taaltjes met het N.E. te onderzoeken, zelfs wanneer er voldoende materiaal voorhanden zou zijn, wat thans nog niet het geval is. Veeleer moeten wij, gelijk werd aangetoond, uitgaan van een samenvatting van deze talen, een taalfamilie dus, die juist thuis hoort in het door Sénégal en Niger ingesloten gebied, en die geheel dit gebied beslaat.

Dank zij de scherpzinnige onderzoekingen van Delafosse en Diedrich Westermann ${ }^{2}$ ), kunnen wij ons een synthetisch beeld vormen van de taal welke gesproken wordt in geheel West-Soedan en Opper-Guinea, een deel van het geboorteland der Surinaamsche slaven. Een vergelijkend onderzoek van acht talen toch: Ewe, Tsji, Gã, Yoruba, Efik, Kunama, Nuba en Dinka, heeft Westermann ertoe gebracht één groote familie van Soedantalen aan te nemen, die zich van Kaap Verde en de Goudkust uitstrekt tot aan het Victoria-meer en Abessynië. De Westelijke helft van deze Soedan-familie vormt dan de taalgroep welke voor ons onderzoek in aanmerking komt. Deze Westelijke groep werd daarna gedurende vijftien jaren door Westermann in details onderzocht, terwijl eindelijk in een breede synthetische studie, welke in 1927

1) Zie voor het geheele probleem der groepeering de overzichtelijke samenvatting bij W. Schmidt, Die Sprachfam. und Sprachkr. p. 92-110.

$\left.{ }^{2}\right)$ M. Delafosse: Vocabulaires comparatifs de plus de soixante langues parlées à la Côte d'Ivoire, 1905. —D. Westermann: Die Sudansprachen 1911. - D. Westermann: Die Westliche Sudansprachen und ihre Beziehungen zum Bantu. Berlin 1927. 
verscheen, zijn resultaten werden samengevat, alsmede prachtig vergelijkingsmateriaal voor de Bantoe- en Bantoïde-talen werd bijeengebracht.

Westermann zelf rekent van de vroeger door hem onderzochte talen vijf tot de Westelijke helft, namelijk: Ewe Tsji, Gã, Yoruba en Efik ${ }^{1}$ ) en van deze schijnen hem de Kwa-talen in het algemeen, en het Ewe in 't bizonder, het zuiverst het algemeen West-Soedaneesch karakter te vertoonen.

Door deze studies zijn wij thans in staat gesteld in plaats van over enkele onderdeelen en over afzonderlijke dialecten of talen als Tsji of Yoruba, over de Soedantaal in het algemeen te spreken, en daarbij dan vóór alles die taaleigenschappen onder het oog te zien, welke geldend zijn voor alle dialecten die ten Zuiden van de Sénégal en de Niger gesproken worden.

Van één bezwaar moeten wij ons echter van tevoren afmaken, daar het niet speciaal deze vergelijking, maar feitelijk elke parallel tusschen het N.E. en de Afr. dialecten en tusschen deze laatste onderling geldt. De Afr. elementen van het N.E. zijn ontleend op een tijdstip, toen niet meer dan een gering aantal woorden van deze talen was beschreven. Daar een grondige kennis van de Soedantalen pas van recente datum is, en het groote ontleeningsproces reeds een paar eeuwen oud mag heeten, laat het materiaal niet steeds een juiste vergelijking toe. Sinds de voornaamste slavenexport heeft het Afr. zoowel in Afrika als in de nieuwe slavenwereld soms groote veranderingen ondergaan. De verschillen tusschen de woordvormen in de Polyglotta Africana van Köelle, uit 1854, en die in de hedendaagsche werken over de West-Soedantalen ${ }^{2}$ ), zijn in hooge mate leerzaam voor de snelheid waarmede tal van woorden in minder dan een eeuw van gedaante verwisselden. Op deze wijze moeten veel aanknoopingspunten zijn verloren gegaan, moeten deze talen zoover uit elkander gedreven zijn, dat een volstrekt juiste vergelijking ten zeerste wordt bemoeilijkt. En eerst naarmate de Africa-

1) p. 3. Die Sudanspr.

2) zie ook Westerm. Die W. S. Spr. p. 86; L. d. M. p. 466. 
nisten erin slagen meer oudere stamkenmerken vast te stellen, en de oudere gedaante dezer talen te reconstrueeren, zullen wij in staat zijn tot in détails parallellen aan te wijzen. Een aantal hoofdzaken kunnen echter dank zij de navorschingen in deze eeuw, reeds worden vastgesteld, een aantal andere parallellen kunnen wij met het voorhanden materiaal reeds aannemelijk maken, of met eenigen grond vooronderstellen.

$\S 2$. De phonetische overeenkomsten. Wanneer men de West-Soedantalen als een eenheid beschouwt, dan is dit minder nog een lexicale, dan wel een phonetische, en een grammatische eenheid. En het is juist merkwaardig te zien, hoe sterk de phonetische kenmerken van de West-Soedantalen in het N.E. behouden bleven, zelfs met overheersching van alle Europeesche invloeden. Even sterk als de raskenmerken stand hielden, bleef ook de phonetiek, het physiologische deel van de taal voortbestaan.

Om een recente methode, die van Wölfel, te volgen, is noodig vast te stellen:

1. overeenkomst in de woordenschat

2. in de vormmiddelen

3. in de syntaxis

4. in het klankstelsel

5. in de algemeene taalbouw, in het taaltype. Wölfel wijst er echter op ${ }^{1}$ ) dat de Creooltalen een geheel apart type van kontaktverschijnselen vertoonen. En voor het N.E. geldt ook wat hij in het algemeen zegt: „Charakteristisch ist es, dasz nahezu immer der Wortschatz nur einer der beiden Sprachgemeinschaften herangezogen wird, während der der anderen gar keine oder nahezu gar keine Rolle spielt. Formativmittel verschwinden nahezu völlig oder werden nur als tote Form übernommen, haben kein Leben mehr innerhalb der newentstehenden Sprache und im Syntaktischen greift man zum Allereinfachsten und entfernt sich meistens gleich weit von beiden (es können auch mehr als zwei sein) zugrundeliegende Sprachen."

Achtereenvolgens zal nu getracht worden te bewijzen

1) P. W. Schmidt Festschrift, 1928 pag. 169. 
dat èn klankstelsel, èn vormmiddelen, èn syntaxis èn woordenschat in sterke mate Soedaneesch gebleven zijn, ondanks het feit, dat in het N.E. de bekende creoliseeringsverschijnselen het klankstelsel beperkter, de vormmiddelen vereenvoudigd doen voorkomen. De woordenschat heeft zich vermengd met die der Europeesche talen. Soms zijn zelfs de Afrikaansche en Europeesche woorden samengevallen.

Voor alles dient echter de phonetische overeenkomst onderzocht te worden.

Sommigen kunnen meenen dat wij hier een précair terrein betreden. Zoo staat Lepsius ${ }^{\mathbf{1}}$ ) sceptisch tegenover de Afr. phonetiek, en hij beweert dat de negers gemakkelijk allerlei klanken veranderen. Westermann is echter een tegenovergestelde meening toegedaan, en zegt: „Wo wir Regellosigkeit und Willkür zu sehen glauben, wird unsere mangelhafte kenntnis daran Schuld sein"' 2). En dit zal voor de phonetiek zeker wel a fortiori gelden.

In ieder geval is er voldoende materiaal om tot een vergelijking van het NE-sche en het Soedaneesche klankenstelsel te komen.

Als oorspronkelijke consonanten van de Westelijke Soedantalen geeft Westermann: $\mathrm{k} t \mathrm{p}$

$$
\mathrm{g}_{\mathrm{n} \mathrm{m}}
$$

Deze zijn in het NE. behouden gebleven. Met de Soedantalen heeft het NE. de volgende explosieven gemeen:

$$
\mathrm{k} g \mathrm{t} \mathrm{d} \mathrm{p} \mathrm{b}
$$

De cerebrale $d$ van sommige talen viel in het NE. samen met d, bijv. Ewe: du „dansen” > NE. du ,dans”.

„Vereenvoudiging" had bijvoorbeeld plaats met de labiovelaren $k p$ en $g b$, die kenmerkend West-Soedaneesch zijn. Bijv. Avikam (Kwa-groep): gbekre „Européen” > NE. bakrà „id.” en Ahlõ (Togo): kpali „rufen” > NE. bari ,id."

Zeldzamer had een modificatie plaats, als met Yoruba: kpe „,vollenden” > NE. ke्nba ,gereed”.(Niet port. acabar!)

$\left.{ }^{1}\right)$ Nubische Grammatik p. XIX vlg.

2) Sudanspr. Pag. 3. 
Van de affricaten die eveneens typisch voor de Soedantalen zijn, bleef kj, dat in 't NE. moeilijk of niet te onderscheiden is van $\mathrm{tj}$. $\mathrm{Tj}$ en dj daarentegen zijn frequent als palatalisatie van $\mathrm{k}$ en $\mathrm{g}$, soms ontstaan uit dž (Ewe: dži „zeugen" > NE. dji "geven"; Engelsch ginger > NE djindja.)

De palatalisatie van $\mathrm{k}$ voor $\mathrm{j}$, e, die nog steeds doorwerkt in het NE (tjejpi < ned. keep, ,sneetje”, tjiri < kill „,id.”) is een oude, algemeen Soed. tendens. In alle Kwatalen heeft de $\mathrm{k}$ voor $\mathrm{i}$ en e palatale uitspraak, en in 't algemeen vertoonen sommige talen palatalisatie van $g$ en $d$; $\mathrm{k}$ werd vaak ook tsj (Togo Restsprachen), en kj (voor i, e en $\underline{\mathrm{e}}$ in de Mandingo-talen), evenals $\mathrm{g}>\mathrm{dj}$.

Voorbeelden Anecho (Togo): ogiga-e „Stachelschwein” $>$ N.E. djindja-maka ,id." Efik: mbake „Korb” > N.E. batji „id." Voor de recente dóórwerking van de palatalisatie-tendens, vgl. vormen als N.E. tjari < eng. carry en N.E. lidjeri $<$ Ned. regeeren; dit laatste nadat Ned. $\gamma>$ N.E. ,g” werd.

Van de alveolaren ts en $\mathrm{dz}$ bleven waarschijnlijk slechts sporen in de uitspraak van t en d, die ik echter nog niet met voldoende zekerheid heb kunnen constateeren.

De meeste Soedaneesche fricatieven bleven behouden: r, l, s, sj, z, f. De h in 't N.E. is zeer onzeker, feitelijk niet meer dan een energieke klinker-aanzet, de $\mathrm{v}$ die in het N.E. onbekend is, werd meestal f. Zeldzaam is de N.E. z $<\mathrm{dz}$, in oorspr. Afr. woorden (N.E. azèmã < Ewe: adze „Hexe”, en van Bantoe-woorden: nzige > azèdjè „kever", nzovu > azaw „olifant”). Afrikaansche $\gamma$ en $\chi$ werden explosief.

In het N.E. is $\mathrm{f}$ dentilabiaal. De Soedaneesche bilabiale $\mathrm{f}$ (en ook v) viel hiermede samen. Het is mogelijk dat het N.E. vroeger toch een bilabiale vorming gekend heeft, waarvan de f/b-wisseling nog over kan zijn. Bijv. N.E. drifi naast dribi ,opschuiven" ${ }^{1}$ ).

De $r$ is in het N.E. evenals in de Soedan-talen een tongenspits $r$, wat defrequente wisselingen van $r$, len d verklaart.

$\left.{ }^{1}\right)$ Vgl. Hesseling, Het Negerholl. op de Deensche antillen, pag. 89.

West Indische Gids XI 
De halfvocalen $\mathrm{j}$ en w bleven, evenals de nasalen $\mathrm{ng}, \mathrm{nj}$, $n$ en $\mathrm{m}$. Afwijkende klanken, zooals de palatolabiale ẃ van Tsji en Gã werd door mij niet waargenomen in het N.E.

Er bestaat geen reden te zeggen dat het N.E. phonetisch bizondere overeenkomst met Tsji en Ewe zou vertoonen. Eerder vertoont het N.E. de grootste verschillen met het Ewe, dat in dit opzicht ook het sterkste van de andere Soedantalen afwijkt. Tsji en Yoruba hebben een vrij eenvoudig consonanten-systeem, waarmede dat van het N.E. meer overeenkomt.

De vereenvoudigingstendens heeft bijna alle samengestelde consonanten uit de grondtaal aangetast. Met name dẃ, fẃ, hw, $\dot{\chi}$, ñw, tẃ en tw. Behouden bleef soms gw, bijv. N.E. dagwè = papasnètji „vaderslang” < Ewe: tógbui, Dahomey: tagwoe „Groszvater”; - en kw, bijv. N.E. kwàta ,aap" < Mende: kwala „Affe”, dat ook aan andere klanken beantwoorden kan, bijv. N.E. kwabu „gezwollen hoofd, bof" < Ewe: gbaboe „Masern”.

Ook dw (Tsji o.a.) en dz (Ewe o.a.) werden N.E. dj. Bijv. Tsji: dwonku > N.E. djonku "heup"; Ewe: Kodzo, Tsji: Kwadwo > N.E. Kodjo; Ewe: Adzóa > N.E. Adjuba.

Nog kent het N.E. sw, dat echter niet oorspronkelijk Soed. is, (met slechts een enkel Bantoe-voorbeeld: maswà „fuik"), terwijl contractie later weer consonant-verbindingen heeft veroorzaakt, bijv. gwè „weggaan” < go away, gwènti < gewend, gewoonte.

Ook de nasaliseeringen bij anlaut, die vele Westelijke Soedantalen kennen, verdwenen evenals de nasale prefixen van de Bantoe-talen geheel in het N.E. Bijv. Tsji: ṅkonkkonsa „Heuchelei” > N.E. gongosà ,id.” Trouwens, veel prefixen, met name de klasse-prefixen werden in het N.E. niet tegelijk met woordstammen overgenomen.

De dubbel-consonanten zijn in 't N.E. evenals in de Soedantalen ontstaan door assimilatie, of tengevolge van contractie. Maar ook in het N.E. wordt de geminatie werkelijk gesproken, speciaal anlautend. (Bijv. N.E. mma „moeder”, ttibri „oude munt”, ssa „,zuster”).Dit verschijn- 
sel werd ook in het bizonder bij het Tsji genoteerd.

De onscherpe scheiding tusschen de lenis en fortis-consonanten van W. Soedan bleef ook in 't N.E. voortbestaan, waar $f$ en $b, m$ en b, g en k wisselen, bijv. drifi 'dribi „opschuiven”, tormàn/torbàn „verklikker”, ju mèn dè/ju bèn dè „gij waart”, fruku/frugu (Wdbk. van Schumann) „vroeg". Dit was ook oorzaak dat intervocalische v meest b werd. (Savana $>$ sabana, eng. heavy $>$ hẻbi etc.); als in het Kpelle (Mandingo) waar $\mathrm{v}$ en $\mathrm{b}$ dialectisch wisselen ${ }^{1}$ ). In ouder N.E. bemerken wij reeds de weifeling, zooals bij Herlein, die „liewy” voor libi, „love” voor „lobi” heeft. Vgl. ook sribi < sleep, frẻdè < frighten.

In alle Soed. taalgroepen wisselen ook r, 1 en d, al kennen enkelen talen toch een consequente differentiatie. De reden van deze wisseling is te zoeken in de kwaliteit van $r$ en l. Een enkele onderzoeker (o.a. Müller) heeft zelfs gesproken van „eine Art schlecht artikulierten $\mathrm{r}$ und l, die ineinander übergehen". Voorname talen als Tsji, Ewe en Gã kennen de $r$ alleen in inlaut, en de wisseling $r / l$ is reeds door een oude onderzoeker als Koelle waargenomen. Het is ook in inlaut dat in de Mandingo-talen r, 1 en d geregeld wisselen. Geen wonder dat dit verschijnsel niet verdwenen is in het N.E., dat niet alleen $\mathrm{r} / \mathrm{l}$ wisseling heeft, (bijv. lèti/rèti „recht”, kali/kari „call”), maar ook $\mathrm{r} / \mathrm{d}$ : prasàra < palissade, en brada „broeder" naast ouder brara < *brothr-o < brother, (voor deze vorm vgl. het Wdbk. van Schumann, het „Njoe Testament”, ed. 1901 etc.), siri < seed, dja < *'ida < here, lusũbẻ < dusũbẻ „duizendpoot”. Teenstra geeft hieromtrent (De Landb. II 207) als merkwaardige bizonderheid: „De in Suriname geboren kinderen hebben door omgang met de slaven een eenigszins verbasterd accent, verwarrende veelal de $\mathrm{r}$ met de 1 en omgekeerd". Deze verwarring kan men nog dagelijks waarnemen bij de holl. sprekende creolen in Suriname.

Hier dient misschien ook gewezen te worden op een eigenaardige, alleenstaande wisseling van $\mathrm{n} / \mathrm{d}$ in het lidwoord $n a$ dat ook als $d a$ genoteerd is. (Schumann; Njoe

1) Het Papiamento kent ook de $v / b$-wisseling op nagenoeg dezelfde wijze als het N.E. 
Testament; Wullschlägel). Dit „da” is iets speciaals van de Duitsche bronnen. Focke noemt als meest gebrulkt „na", 1 ) en in de tegenwoordige spreektaal hoort men steeds $n a$ of $a$ als lidwoord, en nooit da. De Soedantalen hebben ook $n a$, dat bijv. in het Tsji juist zoo gebruikt wordt als in het N.E. Vgl. het Negerholl. waar soms $d a$ gebruikt is naast na ${ }^{2}$ ).

Eindelijk zegt Westermann $\left.{ }^{3}\right)$ : „Uberaus zahlreich sind die Fälle in denen $\mathrm{n}$ zu l wird". Hiervan ken ik slechts één voorbeeld in het N.E. en wel nanga (,en, met”) dat bij Teenstra als „lange” genoteerd staat, en in Focke's Woordenboek als "lánga”, variant van nanga. Voorts aldaar mortiri, terwijl Wullschlägel Wdbk. 163 montiri heeft, welke laatste vorm de thans gebruikelijke is.

§3. Klank wisselingen. De vocalen van $W$. Soed. werden in het N.E. bijna alle behouden. De Afr. groepen kenden slechts de korte a, evenals het N.E. dat slechts zelden een gerekte ā heeft vóór $\mathrm{r}$ (N.E. djāri < port. jardim) of vóór $\mathrm{n}$ (māndi = eng. mind?), en een $\bar{a}$ uit o ontstaan. bijv. sāfri < soft, sāri < sorrow, wat intusschen ook als rekking (vóór r) moet beschouwd worden van a $<$ o (vgl. toch de korte a in brada $<$ brother, natji $<$ knock etc.).

é (als in zee) e (als in we, te) en è (als in pit) bleven in het N.E. (fréfré, têtà, lèba). De $e$ (als in bed) die in alle W. Soed. talen voorkomt, werd N.E. > è (Grebo: ńine „Frau" $>$ N.E. nẻnè, Kwa-talen: koko-be „rein niet-zijn” > N.E. kokobẻ „melaatsch"), of i (Efik, Ewe: bake > N.E. batji „korf”).

Lange en korte i werden N.E. i, daar de lange $\bar{i}$ in het N.E. slechts als emphatische rekking voorkomt. (firi ,,voelen”, liba „rivier”; sitji „ziek" naast sītji „zeer ziek”).

1) In voce „na” verwijst Focke naar een voetnoot: „Ofschoon $\mathrm{Na}$ om de welluidendheid algemeen voor Da gebruikt wordt, heb ik overal steeds Da behouden."

Dit „Da” schijnt dus slechts een fictieve vorm te zijn.

2) Tijdschrift voor Ned. Taal en Lett. XXX, pag. 131-132, noot. Hesseling: Het Negerholl., p. 111 voetnoot, is geheel onjuist.

') W. S. Spr. 201. 
De geronde klinkers ö (neus), ö (put) en ü (vuur) van sommige Soedantalen komen in het N.E. evenmin voor als in vele oudere Soedandialecten.

Open en gesloten o werden in het N.E. de eigenaardige „0" die meestal kort is en slechts lang in rekking, wederom vóór $\mathrm{r}$ (bōri), vóór $\mathrm{n}$ (sōndu < zonde) of uit diphtong ou, oi ontstaan (sōtu < zout, pōri < spoil). Bijv. Kwa-talen: ṅmōtō „schlammig” > N.E. moto-moto „modder"; Yoruba: óni „Biene” > N.E. oni „bij”.

Dat de twijfelachtige kwaliteit van Soed. o overeenkomst heeft met die van N.E., bewijst de opmerking van Delafosse ${ }^{1}$ ), „6 se prononcera comme un o très fermé, presque ou." En dit is in het oudste N.E. reeds overgenomen, gelijk blijkt uit de verschillende spellingspogingen om de kwaliteit van deze vocaal grafisch te benaderen. Zoo schrijft Herlein (1718) in zijn gesprekken, pag. 121 vlgg.: „oudy" voor odi, „gaeu” voor go, „,bie laeu” voor bilò, „hause” voor oso, „bosse” voor bosi (kussen). Hij heeft met naïve nauwkeurigheid deze o dus met ou, au, aeu en o plus cons. willen benaderen ${ }^{2}$ ). De tegenwoordige kwaliteit nadert inderdaad nog die van u, hoewel daarnaast een jongere $\hat{o}$ (poot) is ontstaan, bijv. kônu $<$ koning, gôtu < goud, die te onderscheiden is van gerekte ō (lōntu, pōti ,arm”), en die nooit voorkomt in auslaut.

Tenslotte hebben de Soedantalen nog korte en lange u (,oe”), in 't N.E. alleen kort gebleven, bijv. Kwa-talen: bubui „Schreckgespenst” > N.E. bubù „,spook", Dinka: abuk „schimmel modder" > N.E. bukù ,beschimmeld" terwijl een lange $\overline{\mathrm{u}}$ ook alweer slechts als emphatische rekking voorkomt. (drungu/drūngu „zeer dronken”).

Sommige Soedantalen als Kpelle (Mandingo-groep) hebben o, e, i, u als „auszerordentlich kurze Vokale” (Westermann) en deze zijn dan ook bij voorkeur in het N.E. gebleven, dat zulke sterke verkortingstendenzen heeft. Merkwaardig is ook, dat van de vocalen met lippenstulping ( $u, u ̈, o ̈, o ̈)$ alleen de u is gebleven, die een zeer voorname plaats in de N.E. woorden inneemt.

$\left.{ }^{1}\right)$ Delafosse Vocab. Comparat., p. 2. - $\left.{ }^{2}\right)$ Evenzoo in het woordenboek van Schumann. Een andere poging doet Wullschlägel Wdbk. p. 35 als hij spelt: vro-oektoe „Frucht” voor froktu. 
Geheel in overeenstemming met de grondtalen kent het N.E. de nasaliseering van alle klinkers in ongedekte positie. Speciaal in auslaut zijn $\mathrm{n}, \mathrm{m}$ en $\mathrm{ng}$ in de Soedantalen vaak slechts als nasaliseeringen van de voorafgaande vocaal behouden, zooals het N.E. dat ook geen nasaal, slechts genasaliseerde vocaal als uitgang kent. Bijv. Tsji: odòkóno ,,boiled bread of maize”, Ewe: yòkúmi „Schibutter" > N.E. dokũ ,gekookte koek", Idjo: fam ",frappe” $>$ N.E. fõ „slaag geven”, Kwa-talen: lõ „traben” > N.E. lõ „rennen”, dat in inlaut geen nasaliseering heeft: lo-wè „wegloopen”.

ng is niet explosief: Tsji : ńkonk kosa > gongosa. Slechts bij uitzondering: jã-ga, ,zich ziek voortsleepen” $<$ Yoruba: šan „sich krank fortschleppen" + *kia, kua „gaan”.

Deze regels gelden ook voor de Europ. ontleeningen als N.E. hẽsri < hengsel, worõ < worm, tjẽ < cane. Soms krijgt een auslautende nasaliseering verschlusz in inlaut, en wordt aldus $m$ of $n$, bijv. fõ naast fom-alési „rijst stampen”, sã naast san-trob'ju („wat scheelt je?”). Vgl. Schumann die „fumm (!) = schlagen" heeft.

Evenals de Soedantalen kent ook het N.E. een muzikale silbentoon, die in bizondere gevallen de sterktetoon kan overheerschen, hoewel in het N.E. deze beide meestal zijn samengevallen. In dit opzicht dienen zoowel de meeste Afr. talen als het N.E. nader onderzocht te worden, hetgeen zonder twijfel met groote moeilijkheden gepaard zal gaan. De emphatische muzikale accenten veroorzaken in het N.E. ook kwantiteitsvermeerderingen (rekking van a, o, è, i, u) bijv. langa en lānga ,zeer lang” (láànga).

Voor de toon als uitdrukking van groot en klein, resp. zéér en weinig in het NE, biedt o.a. het Ewe een treffende parallel. De hooge toon geeft daar in sommige gevallen iets lieflijks en kleins, de diepe toon daarentegen iets groots en angstwekkends te kennen ${ }^{1}$ ). Vgl. N.E. a no

1) Vgl. W. Czermak: Zum kons. Anlautwechsel in den Sprachen des Sudan, Festschr. W. Schmidt. Ook Westermann in Festschr. Meinhof, p. 212 en Beiheft MSOS XXIX, Delafosse in Les langues du m. p. 474, en daartegenover Westermann: Die Sudanspr., p. 81. 
hèbi (tiefton!) en a hèbi (hochton, stijgend-dalend) so tè (hochton).

Uiteraard heeft de toon echter in de West-Soedantalen, die echte "Tonsprachen" zijn, een grootere beteekenis dan in het N.E. Toch heeft ook hier de toon soms nog een etymologische waarde, en brengt zij een fijne, voor vreemdelingen nauwelijks merkbare onderscheiding van homonymen. Zoo neem ik aan: áti ( < Ewe: éti „hart”) àti ( < hat „hoed”) àti (< hurt „pijn”). 't Is het duidelijkst waar te nemen in zinnen als: mi át'e àt mi „mijn hart doet pijn mij” en: mi àt'è nàti „mijn hoed wordt nat”. Vgl. nog át "bròn „hartebrand" = woede, en àt 'oso „pijnhuis" = hospitaal.

Evenzoo: ál „ja” (< a dè „het is zoo”), àl „boontje, pitje” < Ewe: ayi „Bohnen, Erbsen”, ài „oog < eng. eye; sútù „schieten” < eng, shoot, en sùtù „steken, stooten” $<$ Ewe: tù, Tsji: tua, Mossi: su, „einstecken, stoszen.”

Door de in het N.E. toegevoegde uitgangsvocaal hebben haast alle meersilbige woorden, welke niet op nasale voc. eindigen, de klemtoon op de voorlaatste lettergreep, die meestal de stamsilbe is. Daar genasaliseerde slotvoc. meestal wèl stamsilbe is, heeft deze vaak het accent. Bijv. wàka, sùtu, maar: worồ ( $<$ worm), sidồ ( < sit-down).

Uitzonderingen zijn oorspr. Afrik. woorden die het accent op de slotvocaal hadden, bijv.: N.E. bakrà ( < Efik: mbakara), dagwè (< Ewe: tagwè), kumbà, gongosà, kokobè, avò ( < Kunama : afã „grootmoeder"), kundù.

Finaal-accent leidt tot contractie in het N.E., evenals in sommige Soedan-talen (N.E. sdõ naast sidồ etc.). Vooral geschiedt dit bij de reduplicaties, die veelal het accent op het tweede deel hebben, bijv. divi-divi, sakasàka, etc. wat tot verzwakkingen leidt als teta naast tatà, gegò naast gogò, en contractieš alsk'kwa naast kwakwà, n'njã naast njã-njằ, welke contracties soms de eenige overgebleven vormen zijn, bijv. wiwiri $(<$ wiriwiri, nog bij Teenstra), en birbiri $<*$ biri-biri, pirpiri naast piri, etc. 
$\S 4$. Gram maticale overeenkomsten. Er bestaat mede een groote overeenkomst tusschen het formatiere systeem van de Westelijke Soedantalen en dat van het N.E. Meersilbigheid is bij eerstgenoemden meestal een gevolg van prefigeering of suffigeering van een of ander "Bildungselement”. De woordstammen zelve zijn haast altijd eensilbig. Nu kwamen voor overname natuurlijk de meestal vaak verwisselde prefixen en suffixen niet in aanmerking, maar slechts zulke affixen die regelmatig terugkeerden, of die een vaste verbinding met de stam vormden.

Zoo zijn dan ook verreweg de meeste woorden in het N.E. evenals in de Mandingo-talen tweelettergrepig, en bestaan zij uit één stamsilbe: (consonant)-vocaal-consonant, plus een vocalische uitgang. De eensilbige woorden zijn of door contractie ontstaan, of uit oorspr. eensilbige van de vorm cons.-voc., of cons.-voc. plus nasaliseering. (bijv. na < Soed: na; go < eng. go; fõ < Soed, fõ ; bõ < ned. boom; krsō < curaçao, krbas-i < kalebas.)

De vocalische uitgang is meestal harmonisch, d.i. gelijk aan de stam-vocaal. Dit geldt speciaal voor de Europ. ontleeningen, want daar de Soed. woorden in de meeste talen zonder uitzondering vocalische uitgang hadden, werd deze mede overgenomen in het N.E. Vandaar dan ook dat vocaalharmonie bij de oorspr. Afrik. woorden veel minder frequent is, dan bij de Europ. ontleeningen.

De vocale, resp. genasalis.-voc. uitgang van het N.E. heeft de plaats ingenomen van de Soed. suffixen, waarvan slechts enkele, en meest nog in min of meer gewijzigde functie, bewaard bleven.

Ook de prefixen verdwenen bijna altijd in het N.E. trouwens soms reeds in de Soedantalen zelve, gelijk Delafosse aantoont ${ }^{1}$ ).

Het is intusschen niet te verwonderen dat het meestvoorkomende prefix van de Soedan-talen, ,a-" ook in het N.E. wordt aangetroffen. De oorspronkelijke beteekenis van dit prefix is onbekend; soms veranderde het door as-

1) Voc. comp., p. 50 . 
similatie. Maar evenals in de Soedantalen heeft het in 't N.E. een drieledige functie. Het maakt daar:

a. verbum tot nomen: swari "slikken" > Akãswari „slokop".

b. appellatiefnomen tot eigennaam: kuri „koelie” > Akuri ,id." ; rat, *latta > Alatta.

c. adjectief tot substantief: makti ,machtig” $>$ Amakti „de machtige".

Meestal is echter de nauwkeurige beteekenis van het prefix niet aan te geven, zooals in N.E. alamun $(<$ lemoen), adompri ( $<$ eng. dumpling?) azaw ( $<\mathrm{Kebu}$, Togo: tšo-e, en Bantoe: nzovu, nzau), ablinka (< Ewe: bliko „Dunkelheit”), aboma (< Bantoe: mboma), abongra ( $<$ Bantoe: mbongo). Adjàka (< Yoruba: adžaka), adjokri ( $<$ Ewe:adzoke) afàna ( < Tsji: afãna) hebben het prefix ook in de Afr. grondvorm.

Er zijn hiervan betrekkelijk veel voorbeelden te vinden $\left.{ }^{1}\right)$.

Het vormen van eigennamen door een geheelen zin, bijv. N.E.: Nomèrimi, Tjakõmidè, Akãswāri, etc.) geschiedt o.m. ook in het Ewe. In het Tsji wordt het „a-" prefix gebruikt om verbaal-substantiva te maken, en het N.E. kent ook een dergelijke vorming, bijv.: a-waka è wēr'ẽ „loopen doet vermoeien hem”, een constructie die voorkomt naast het aoristische waka wēr'èn „loopen vermoeien hem". In het eerste geval treedt door het verbaalsubstantief praesens in de plaats van aorist. In deze functie toont het ,a-" prefix overeenkomst, zooal geen identiteit met het lidwoord en het pron. personale 3 sing. ,a" in het N.E. (< Soed: a „pron. pers. 3 Sing.”).

Gelijk voorts nog uit de dag-namen der negers blijkt, is A- voor eigennamen ook een soort van vocatief-prefix geworden, bijv. A-banku, A-bjensi, A-pàtu, bij vrouwen Abèna, A-mejija. Zie voor verdere voorbeelden Encycl. v. Ned. W.-I., pag. 501 vlgg. In alle bovengenoemde gevallen is contaminatie met het alg. Soed, demonstratiefpronomen „na” niet uitgesloten geweest.

In andere gevallen is het a-prefix in het N.E. verdwenen, bijv. N.E. kaka „haan” < Yoruba: akuko „id”.

1) Voor de Bantoe-woorden zie Hoofdstuk III. 
naast vormen als in Ewe, zonder prefix; batji $<$ Ewe: abake naast Efik: mbake etc.

Onder de Soedaneesche suffixen heeft ,*-li" verreweg de belangrijkste beteekenis, terwijl het ook als geinfigeerde $\mathrm{r}, 1$ optreedt. In de Kwa-talen dient het bijv. tot het vormen van infinitieven, en in deze functie is het in 't N.E. ook terug te vinden als uitgang i na liquida, in oorspr. Afr. of Europ. woorden. Bijv. Ahlõ(Togo): kpali „rufen” > N.E. bāri „id”"; Mandingo-talen: tali, Ewe: tó „erzählen” $>$ N.E. tori (in tori-man ,verteller”). De vocaal in „-ri” als infinitief-suffix, bleek sterker dan de latere neiging tot vocaalharmonie. Zoodat het N.E. thans een geheele reeks „onharmonische” verba op -ri kent, bijv. hori, hari, pari, sōri, kōri, bōri, kāri, pōri, sēri, wēri, mēri, swāri sāri. Harmonisch zijn piri en firi, terwijl tjurì $<$ Soed. *gịuli ,schelten, schimpfen” (Westerm. Sudanspr. Stam no. 115) een zeldzaam voorbeeld is van klemtoon op het suffix, hoewel ook tjùri door mij genoteerd werd, evenals harm. tjurũ.

De Afrik. woorden hebben ook nog andere invloed uitgeoefend op de vocale dissimilatie van N.E. uitgangen. Bijv.eng.ring > N.E. linga onder invl. van Tsji: kā, Gã : ga „ring”. Evenzoo bij dagu (eng. dog naast Ewe: avù), butà (eng. boot naast Yoruba: bata „Schuh”) didõ (eng. lie down naast Alaguian = Lag. talen: deda ",dormir") etc. De voorbeelden hiervan zijn talrijk, en ook Schuchardt heeft een dergelijke inwerking van twee woorden op elkander in beginsel waarschijnlijk geacht.

Minder belangrijk zijn de enkele vocaalomstellingen in het N.E., die ook in de Soed. talen zeldzaam zijn. Bijv. gàdo < god? of Ewe: Gbadu „Kpōli-Godheid”.

De twee voornaamste W.Soed. infixen vinden wij ook op typische wijze in het N.E. Het r-infix (*-ri) kwam in Europ. ontleeningen voor, als N.E. rèbritji ( < ned. ribbetje), wèrdri ( < ned. wild).

Het n-infix (,,innere Nasalierung”) dat ook Schuchardt voor het Saramakkaansch als "Nasaleinschub" heeft waargenomen ${ }^{1}$ ), vinden wij zeer vaak in het N.E., bijv.

$\left.{ }^{1}\right)$ H. Schuchardt: Die Sprache der Saramakkaneger... pag. 118 Nachtr. 
nèngrè < nigger; mangi < mager, port. mogro; mindri $<$ middle; nangra < nagel; kũsu < cushion etc. Soms in auslaut: njũ $<$ new, naar analogie met njũsu $<$ news.

Wie ook slechts oppervlakkig het N.E. kent, wordt getroffen door de talrijke reduplicaties die bij alle woordsoorten gevonden worden. De reduplicatie-tendens is zelfs nog steeds actief, en de Creool maakt dagelijks nieuwe reduplicaties.

$\mathrm{Nu}$ zijn de woordverdubbelingen in de W.Soed. talen eveneens opvallend talrijk. Zij dienen daar meestal om:

1o. verbaalnomina en adjectiva van verba te vormen.

2o. om infinitieven te vormen, en als conjugatie.

3o. om diminutiva te vormen.

4o. als versterking van adverbia.

5 o. om het meervoud van sommige woorden te vormen.

6o. om wederkeerige handelingen uit te drukken.

7o. als „Lautbilder”.

Hierbij moet opgemerkt worden, dat in de eerste silbe van het dubbelwoord vocaalverenging plaats heeft.

Gelijke functie hebben ook de reduplicaties in het N.E. Van het werkw. fõ het subst. fõfõ „slaag”, van krabu krapkrabu „schraapsel”, van tai tetai „bundel”, van njã njenjã ,voedsel”, van kosi koskósi „,scheldwoorden”.

Speciaal werktuignamen vindt men veelal als reduplicaties van de werking: van griti gritigriti „rasp”, van kã kãkã „haarkam”, van nai nenai „naald”, van sibi sisibi (<*sibi-sibi) „bezem” etc.

Ook adjectiva worden als verdubbeling van een verbum gebruikt, bijv. van broko broko-broko „half en half”, van brõ brõbrõ „,aangebrand”, van piri pir-piri „kaal”.

Het N.E. maakt voorts infinitieven van een bepaalde beteekenis door reduplicatie; hoofdzakelijk frequentativa en intensiva.

Van de eerste soort bijv. van waka wakawaka „drentelen”, van broko brokobroko ,in stukjes breken”, van tatji tak'tatji „,wauwelen”, van pré prépré „frunniken”, nat'nati „besprenkelen”, dègrè-dègrè „waggelen”, enz. Als intensiva bijv. van kōri kōr-kōri „vleien”, van sètji sèk'sėtji „door elkaar schudden”, enz. 
Diminutiva vormt het N.E. mede door verdubbeling, zooals van busi bus'busi ,heesterboschjes”, van pisi pispisi „snippers”. Ook birbiri ,laag gras”, en bisbisi ,,kleine wormpjes" waarvan de enkel-vorm niet aangetroffen wordt.

Versterking van adverbia geschiedt regelmatig door verdubbeling: krikrí „geheel en al”, wantẽ-wantẽ "onmiddellijk", sréf'sréfi „,juist”, tanji-tanji „als 't u blieft”, hès-hẻsi „zeer snel”. Ook kwètkwèti "absoluut niet”, mamà „,zeer groot” en nono „neen”, hoewel hiervan de enkel-vorm niet gebruikt wordt.

De meervouds-beteekenis van sommige reduplicaties is vooral duidelijk bij substantieven, bijv. wiwiri (nog bij Teenstra wiri-wiri) "gebladerte" jaga-jaga „vodden", pis-pisi „stukjes".

Waarschijnlijke dualis vinden wij in gogo „,billen”, pãpã „cunnus", tutu „horens”, sùsu „schoenen” en sesé "schaar". Merkwaardig is dat de meeste dezer meervouds-reduplicaties ook in het enkelvoud geredupliceerd worden, denkelijk door analogiewerking. Bijv. wã sùsu, wã wiwìi.

Voor de uitdrukking van wederkeerige handelingen bestaan geen afzonderlijke reduplicatie-vormen. Wel wordt vaak occasioneel verdubbeld om de wederkeerigheid uit te drukken, zooals in zinnen van het type: Sã w'è tjitjitjitji makandra? „Waarom jullie rukken elkaar?” In deze zin vond zelfs verdubbeling van een reeds geredupliceerde vorm plaats.

Het N.E. kent tenslotte tallooze geredupliceerde „Lautbilder”, bijv. kwakwa „eend”, djẽ̃djẽ ",bel”, tiko-tiko „hik", srí-sri „krekel”, wũwũ „hommel”. Mogelijk vallen onder deze rubriek ook de tallooze diernamen, die het N.E. geredupliceerd kent (montji-montji, kami-kami, tjotjo, wara-wara. etc.). Doch het niet geringer aantal plantnamen in dubbel-vorm maakt eerder een andere groepeering wenschelijk.

Niet alleen van de plant- en dier-namen die elders afzonderlijk onderzocht worden, maar ook van de overige reduplicaties zijn verschilllende oorspr. Afr. Ik noem slechts: birbiri (Ewe béle-béle „feucht”, Yoruba: bere 
„Gras zum Dachdecken”), bóbo „suf” (in de meeste W.Soed. talen: bóbo „stumm sein”.) bubù (Ewe: dzobú „Framboesia”, bùbu „lahm sein” — ook Kwa-talen: bubu-i „ein Schreckgespenst”), dedoi „sussen” (Tsji: dwudwo „ruhig werden”), didõ „liggen” (Lag. talen: deda „dormir”), Djèdjè „Plaatsnaam” (Ewe, Okpoto: džidži „weit-sein") ès'èsi „snel” (Efik: isa-isa „hastily”), fjofjo „wants” (Ewe yó, yóe „Wanze”), fõfõ (Idjo: fam. Ewe: fò „slaan”), fréfré „vlieg” (Logba, Togo: fle „fliegen”), gãgã „oudje” (Soed. kaka, kaga „grootmoeder”), gõgo-sa (Gã : koko-nsa, Tschi: ṅkonkoṅsa „Heuchelei”) kajakaja „kaal” (Mandingo: kolokolo „ohne Federn”), kàka (o.a. Tsji: akókò „hen”), kèkè „spoel” (Kwa-talen: kèké „spindel”), kèskèsi (Ewe kése „Affe, Pavian”), kóko „pit” (Tsji: koko „Korn, Klümpchen”), kúku ,gezwollen milt”" (Ewe kù, Gã kuku-li „Klumpen”), kur'kùru „korf” (Kyama, Lagune-t.: akŏre „corbeille”) kwakwa „eend” (Ewe, Togo: kpakpahe „Ente”), moto-moto „modder” (Kwa-talen: ṅmoto „schlammig”), nat'nati „besprenkelen” (Gã, Tsji: ṅwãtã-ñãtã „gesprenkelt”), Nenà „,eigennaam van oude vrouwen”, (Gã: nã, Nupe: nna „Mutter"), nènè „,aanspreekvorm vrouwspersoon"(Ewe: nốnù, Kru-t.: ńine, Mandingo-t.: nēn „Frau”), popò „week” (Ewe: bòbò „weich sein”), sesé „schaar” (Kwa-t.: zize „spalten”, Ewe: sáksè „Schere”), textà „vader” (Togo: teté „Vater”), tiko-tiko „hik” (Kwa-t.: hiko-hiko, šiko šiko "Schluchzer”), tòdo „waggelend” ( $<$ dóddo bij Schumann. Ewe: do „bammeln”) tõtõ „gestampte bananen" (Tsji: tùmtùm, Lagune-t.: ètuã), waswàsi „wesp" (Ewe: w่áwã̃ „Wespe”).

Niet geheel zeker is de herkomst als reduplicatie van fufuru, „stelen”, njãnjã „voedsel”, nòno, „neen”, sakasàka, „,bezinksel", wiwiri, „gebladerte”, en wowojo „markt”. Djếdje் ,gogò,jèjè, tutù hebben Bantoe-herkomst.

Sommige W. Soed. talen hebben vocaal-verenging in het eerste redupl. deel. Vgl. N.E. didõ. Bij de verba volgt achter de verdubbeling meestal -e of -i. Hierdoor kwam toen in het N.E. contractie plaatsvond, het accent meestal op het tweede reduplicatie-deel, bijv. tõtồ, dedòi, 
popò, en naar analogie wakawàka, etc. Zoodat vaak verzwakking van 't eerste deel volgde, en soms zelfs de zwakste lettergreep geheel werd uitgestooten. Bijv. nenai, si-sibi ( $<$ sibi-sibi), wiwiri ( $<$ wiriwiri). Het hedendaagsche N.E. heeft zelfs s'sibi, w'wiri, etc. Deze redupl. zijn dus op weg om tot hun enkel-vorm terug te keeren.

Samengestelde woorden worden in de W.-Soed. talen meestal door juxtapositie gevormd; het N.E. vormt op gelijke wijze zijn composita, bijv. grõ-tàpu ,aardbodem”" libi-sma „levend-mensch” etc.

De Mandingo-talen vormen veel samenstellingen o.a. met -no „Persoon”, evenals N.E. wroko-mã, watji-mã, sitji-mã, obia-mã etc. en bũ-sma, bidji-sma, nèngrè-smaetc.

Een andere samenstelling is Kpelle: -séni, Malinke: -hani „Ding”. Deze laatste vorming vinden wij evenzoo terug in het N.E. Bijv. wroko-sani „,werktuig”, pré-sani „speelgoed”, sukru-sani „suikerwerk”, gado-sani „godgewijde dingen" etc.

Talrijk zijn in de Mandingotalen ook de verbindingen met -ke „maken" dat N.E. *-ki > -tji werd, hetwelk zich als onharmonische uitgang handhaafde, bijv. in mètji „maken”, sètji „schudden”, natji ,slaan”, tatji „,zeggen”, watji „bestaren”. Pitji „beantwoorden”, ditji „delven”, witji „wekken” hebben uiteraard regelm. harm. uitgang.

Tenslotte is ook de contractietendens, die nog steeds en in zoo sterke mate in het N.E. werkzaam is, oorspr. uit de W.-Soedan-, meer speciaal uit de Kwa-talen afkomstig, die veel „Vocalausfall” kennen. Toch zijn met uitzondering van de reduplicaties de oorspr. Soed. woorden in het N.E. niet verkort, daar hun stammen toch bijna altijd éénsilbig waren, zoodat contractie niet mogelijk was. Latere Eur. ontleeningen vertoonen echter zeer vaak dit verschijnsel, bijv. schelling $>$ N.E. sré, bottelary $>$ N.E. botri, Sp. azucar > N.E. sukru etc.

Afr. zoo niet van afkomst dan toch van formatie zijn de vele klanknabootsingen die het N.E. gebruikt en die ook talrijk zijn in de Soed. (en Bantoe)-talen. Bijv. a fadõ so prã ; Dagu tatji: pjakũ pjakũ, sã na f' mi na f' mi, etc.

(Wordt vervolgd.) 